\title{
Cholinergic properties of new 7-methoxytacrine-donepezil derivatives
}

\author{
Vendula Sepsova ${ }^{1,2}$, Jana Z. Karasova², Gunnar Tobin ${ }^{3}$, Daniel Jun ${ }^{1}$, Jan Korabecny ${ }^{1,2,9}$, Pavla \\ Cabelova $^{4}$, Katerina Janska ${ }^{4}$, Jan Krusek ${ }^{5}$, Kristyna Skrenkova ${ }^{6}, K^{2}$ imil Kuca ${ }^{2,9}$, Marian Valko ${ }^{7,8}$ \\ and Ondrej Soukup ${ }^{1,2,9}$
}

1 Depatment of Toxicology and Military Pharmacy, Faculty of Military Health Sciences, University of Defence, Trebesska 1575, 50001 Hradec Kralove, Czech Republic

2 Biomedical Research Center, University Hospital, Sokolska 581, 50005 Hradec Kralove, Czech Republic

3 Department of Pharmacology, Institute of Neuroscience and Physiology, The Sahlgrenska Academy at Gothenborg University, Gothenborg, Sweden

4 Department of Pharmaceutical Chemistry and Drug Control, Department of Pharmacology and Toxicology Faculty of Pharmacy, Charles University, Heyrovskeho 1203, 50005 Hradec Kralove, Czech Republic

5 Institute of Physiology Academy of Science of the Czech Republic v.v.i., Videnska 1083, 14220 Prague, Czech Republic

6 Department of Physiology, Faculty of Science, Charles University, Vinicna 7, 12843 Prague, Czech Republic

7 Department of Physical Chemistry, Faculty of Chemical and Food Technology, Slovak Technical University, Radlinskeho 9, 81237 Bratislava, Slovak Republic

8 Center for Basic and Applied Research, Faculty of Informatics and Management, University of Hradec Kralove, Rokitanskeho 62, 50003 Hradec Králové, Czech Republic

9 Prague Psychiatric Center/National Institute of Mental Health, Prague, Ústavní 91, Prague, Czech Republic

\begin{abstract}
Organophosphorus nerve agents inhibit acetylcholinesterase (AChE) which causes the breakdown of the transmitter acetylcholine (ACh) in the synaptic cleft. Overstimulation of cholinergic receptors (muscarinic and nicotinic) by excessive amounts of ACh causes several health problems and may even cause death. Reversible AChE inhibitors play an important role in prophylaxis against nerve agents. The presented study investigated whether 7-methoxytacrine (7-MEOTA) and 7-MEOTAdonepezil derivatives can act as central and peripheral reversible AChE inhibitors and simultaneously antagonize muscarinic and nicotinic receptors. The possible mechanism of action was studied on cell cultures (patch clamp technique, calcium mobilization assay) and on isolated smooth muscle tissue (contraction study). Furthermore, the kinetics of the compounds was also examined. CNS availability was predicted by determining the passive blood-brain barrier penetration estimated via a modified PAMPA assay. In conclusion, this study provides promising evidence that the new synthesized 7-MEOTA-donepezil derivatives have the desired anticholinergic effect; they can inhibit AChE, and nicotinic and muscarinic receptors in the micromolar range. Furthermore, they seem to penetrate readily into the CNS. However, their real potency and benefit must be verified by in vivo experiments.
\end{abstract}

Key words: Acetylcholinesterase inhibitors - Nicotinic receptors - Muscarinic receptors Bladder - Prophylaxis

\section{Introduction}

As recently evidenced in Syria, organophosphorus nerve agents such as sarin, soman or VX can still be a life-threat

Correspondence to: Kamil Kuca, Biomedical Research Center, Sokolska 581, 50005 Hradec Kralove, Czech Republic

E-mail: kamil.kuca@fnhk.cz for the general public. They cause inhibition of acetylcholinesterase (AChE, 3.1.1.7), which is the enzyme responsible for the decomposition of the transmitter acetylcholine (ACh) in the synaptic cleft. AChE inhibition causes accumulation of ACh in the synaptic cleft and thereby overstimulation of nicotinic (nAChR) and muscarinic (mAChR) receptors. Muscarinic symptoms (blurred vision, hypersecretion in the airways, sweating, bronchoconstriction, gut hypermo- 
tility, etc.) and nicotinic symptoms (weakness and muscle fasciculation, tachycardia and hypertension) arise within a few minutes after intoxication. Effects in the CNS are usually non-specific and include headache, anxiety, confusion etc. (Bajgar 2005).

Besides treatment involving the combined administration of atropine and oxime reactivators (Kassa et al. 2002), prophylaxis against nerve agents is another approach. Reversible AChE inhibitors play the most important role in this approach. In general, the carbamate pyridostigmine (bromide) is the most common agent used by army personnel worldwide. The armed forces of the Czech Republic use PANPAL, containing pyridostigmine in combination with two anticholinergics - benactyzine and trihexyphenidyl. The latter two compounds prevent the adverse effects caused by pyridostigmine and protect the central nervous system from the cholinergic crisis. The latter protective effect is not exerted by pyridostigmine because of its poor penetration of the blood-brain barrier (BBB). The focus is on a new approach inspired by the PANPAL strategy, where two drugs with an "opposite" mechanism of action on the cholinergic system are combined. With these ideas in mind, we designed a prophylactic agent which should be able to act as a central and peripheral reversible AChE inhibitor and simultaneously antagonize muscarinic and nicotinic receptors.

Specifically, 7-methoxytacrine (7-MEOTA) was designed and approved for military use against incapacitating agents based on cholinergic overstimulation (BZ compound). 7-MEOTA is a pharmacologically equivalent but less toxic analogue of the parent tacrine. It also possesses a centrallyacting reversible AChE inhibition profile (Dejmek 1990) with complex cholinergic properties (Soukup et al. 2013). The novel series of compounds are based on 7-MEOTA and another potent AChE inhibitor (AChEI), donepezil, which also exerts low antimuscarinic and antinicotinic properties (Ago et al. 2011).

Recently, binary compounds with antimuscarinic and anticholinesterase effects have been synthesized (Leader et al. 2002). Some of them provided better in vivo protection than pyridostigmine alone (Meshulam et al. 2001). From this point of view, 7-MEOTA-donepezil-like hybrids represent an interesting group of modulators whose advanced cholinergic properties are of a high interest not only due to their prophylactic potential but also due to a unique combination of two such pharmacophores in a single molecule (Korabecny et al. 2014). The structure of these derivatives is detailed in Figure 1.

The aim of the presented study was to clarify the mechanism of action of 7-MEOTA on the cholinergic system. Three selected donepezil-like hybrids were selected and their effects were studied on AChE and muscarinic and nicotinic receptors. Furthermore, in order to predict their bioavailability in the CNS, the passive blood-brain penetration of the novel compounds was evaluated.

\section{Materials and Methods}

\section{Chemicals}

All assayed inhibitors were synthesized at the Department of Toxicology, Faculty of Military Health Science, University of Defence, Hradec Kralove, Czech Republic (Korabecny et al. 2014). Purity (>99\%) was assessed using TLC and HPLC methods as described before (Jun 2007, 2008). Phosphate buffer, human recombinant AChE ( $h r \mathrm{AChE})$, DTNB (5,5'dithiobis (2-nitrobenzoic) acid), acetylthiocholine (ATCh), D-MEM (Dulbecco's modified Eagle's medium), nicotine, ACh (acetylcholine), oxotremorine-M (Oxo-M), BQCA (benzylquinolone carboxylic acid), atropine, geneticin, Hank's balanced salt solution (HBSS buffer), dimethylsulfoxide (DMSO), dodecane and donepezil were purchased from Sigma - Aldrich (Prague, Czech Republic). NaCl, $\mathrm{KCl}, \mathrm{CaCl}_{2}, \mathrm{KH}_{2} \mathrm{PO}_{4}, \mathrm{MgSO}_{4}, \mathrm{NaHCO}_{3}$ and glucose used for Krebs solution, and ATP (adenosine-5'-triphosphate) and metacholine $(\mathrm{MCh})$ were from Sigma Chemicals (Co, St. Luis, MO, USA). Probenecid and Fluo-4 NW reagents were from Invitrogen (Carlsbad, CA). Porcine polar brain lipid (PBL) was purchased from Avanti Polar Lipids, Inc. (Alabaster, AL).

\section{AChE kinetic study}

The activities of $h r A C h E$ were evaluated by the adopted spectrophotometric Ellman's method. ATCh (various concentrations) was used as a substrate and DTNB $\left(2.5 \times 10^{-3}\right.$ $\mathrm{mol} / \mathrm{l}$ ) was used as the chromogen. Based on previous experiments a wavelength of $412 \mathrm{~nm}$ was used. The absorbance was determined using a Helios Alpha (Thermo Scientific, Great Britain) spectrophotometer. The in vitro measurements were completed according to the following protocol: $650 \mu \mathrm{l}$ of phosphate buffer $(0.1 \mathrm{~mol} / \mathrm{l}, \mathrm{pH} 7.4)$ was pipetted into the cuvette. Subsequently, $25 \mu \mathrm{l}$ of $h r$ AChE, $200 \mu \mathrm{DTNB}$ and $25 \mu \mathrm{l}$ of the selected AChEI in concentrations from $10^{-8}$ to $10^{-3} \mathrm{~mol} / \mathrm{l}$ were added. This mixture was then incubated for $5 \mathrm{~min}$ at laboratory temperature $\left(22 \pm 2^{\circ} \mathrm{C}\right)$. The enzymatic reaction was started by adding ATCh $(100 \mu \mathrm{l}$, various concentrations). The mixture was gently shaken and measured in duplicates. The values of the controls, in which phosphate buffer replaced the $25 \mu \mathrm{l}$ of inhibitor, were subtracted from the experimental values.

The results were analyzed by GraphPad Prism 5.0 (San Diego, CA). The constants were calculated from enzyme kinetics using Lineweaver-Burk plot and a double reciprocal plot. The AChE dissociation constant for enzyme- 
<smiles>Nc1c2c(nc3ccccc13)CCCC2</smiles>

tacrine<smiles>COc1cc2c(cc1OC)C(=O)C(CC1CC3CCCCC3C1)C2</smiles>

donepezil<smiles>COc1ccc2nc3c(c(N)c2c1)CCCC3</smiles>

7-methoxytacrine

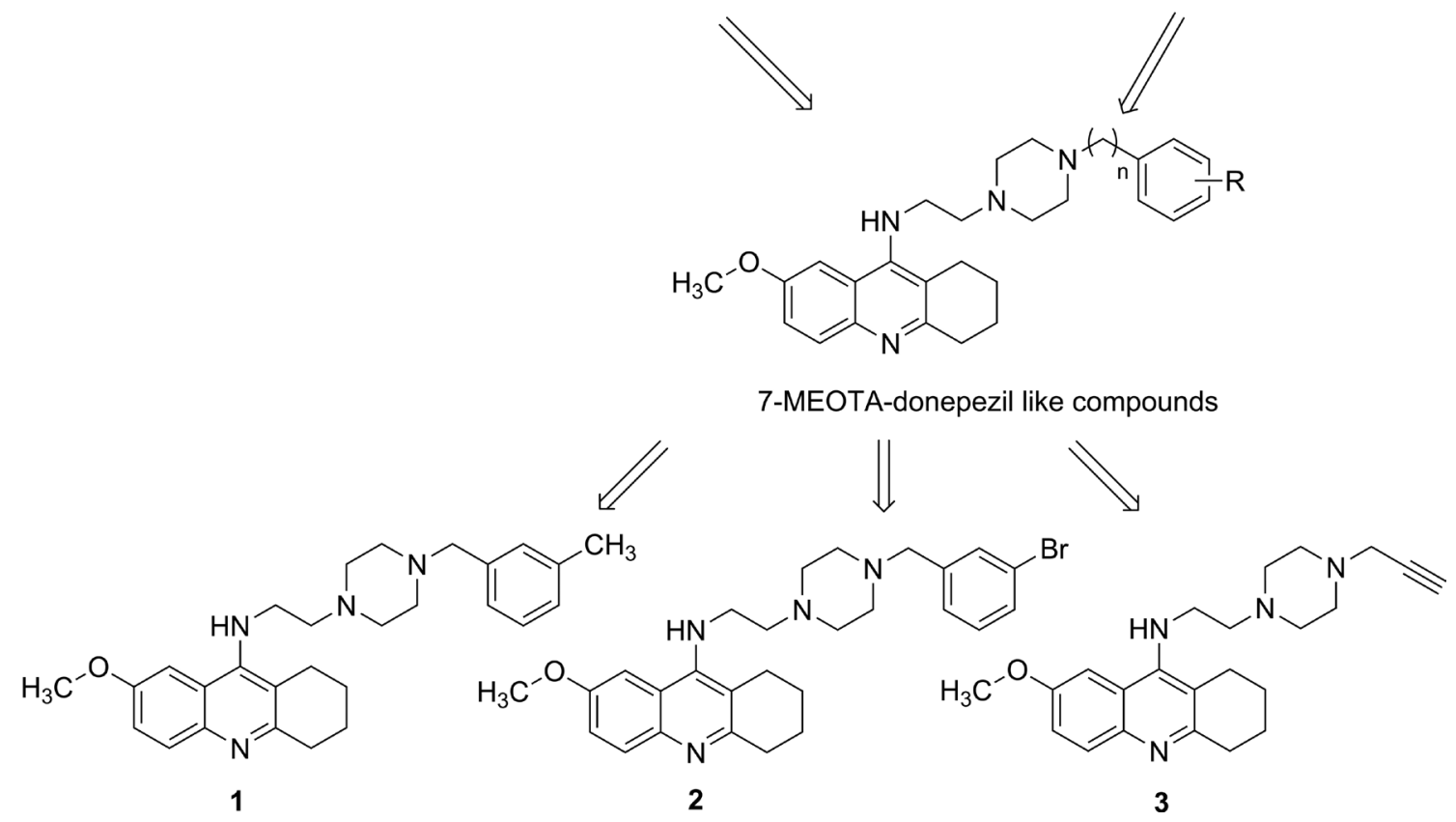

Figure 1. General structure of 7-MEOTA-donepezil like hybrids and derivatives 1, 2 and $\mathbf{3}$ used in this study.

inhibitor complex $\left(K_{\mathrm{i}}\right)$ was calculated using the following equation:

$$
K_{i 1}=\frac{[E][I]}{[E I]}
$$

where $K_{i 1}$ is dissociation constant for enzyme-inhibitor complex; $[E]$, concentration of AChE; $[I]$, concentration of inhibitor; $[E I]$, enzyme-inhibitor complex concentration.

\section{Patch clamp study}

\section{Cell culturing}

Experiments were performed on the TE671 cell line (kindly provided by Dr. Jan Ríčný), which is a medulloblastoma/ rhabdomyosarcoma cell line endogenously expressing human embryonic muscle type receptor $\alpha_{1} \beta_{1} \gamma \delta$ (Schoepfer 1988). Cells were cultivated at $37^{\circ} \mathrm{C}$ under $5 \% \mathrm{CO}_{2}$ atmosphere in Dulbecco's Modified Eagle's Medium (D-MEM), which was supplemented with $10 \%$ fetal calf serum. Nicotine
( $100 \mu \mathrm{mol} / \mathrm{l})$ was added to the cultivation medium $2-5$ days before measurement to increase expression of nAChRs (Ke et al. 1998).

\section{Experimental assay}

The direct effects of AChEIs were measured according to the previous protocol (Soukup et al. 2011). Cells were held at $-40 \mathrm{mV}$ during the recordings. Fire-polished glass micropipettes with an outer diameter of approximately three $\mu \mathrm{m}$ were filled with a solution of the following composition (in mmol/l): CsF 110, $\mathrm{CsCl} 30, \mathrm{MgCl}_{2}$ 7, $\mathrm{Na}_{2}$ ATP 5, EGTA 2, HEPES-CsOH 10, $\mathrm{pH}$ 7.4. The resulting resistances of the microelectrodes were between 3 and $5 \mathrm{M} \Omega$. The cell bath solution contained (in mmol/l): $\mathrm{NaCl} 160, \mathrm{KCl} 2.5, \mathrm{CaCl}_{2}$ $1, \mathrm{MgCl}_{2}$ 2, HEPES-NaOH 10, glucose 10, pH 7.3. Solutions of the tested compounds were applied using a rapid perfusion system (Mayer et al. 1989) consisting of an array of ten parallel quartz-glass tubes, each approximately $400 \mu \mathrm{m}$ in diameter. Tubes were positioned in the vicinity of the recorded cells and the flow of various solutions was 
switched on/off under microcomputer control (Dittert et al. 1998). A complete change of the solution around the cell could be achieved in 30 to $60 \mathrm{~ms}$. For signal recording and data evaluation, an Axon Instruments Digidata 1320A digitizer and pClamp9 software package were used (Axon Instruments, Foster City, CA). Data were low-pass filtered at $1 \mathrm{kHz}$ and digitized at $2 \mathrm{kHz}$.

ACh $(100 \mu \mathrm{mol} / \mathrm{l})$ was used in the assay as control. Any tested compound was pre-applied (5s) and then co-applied with ACh $(100 \mu \mathrm{mol} / \mathrm{l})$. The relative inhibition rate was determined as the ratio of the amplitude of the response to the agonist under the inhibitor to the arithmetic average of two adjacent experimental responses to the controls. At least a $30 \mathrm{~s}$ wash out period was applied between each measurement, so that the cell was washed by the extracellular solution and desensitized receptors were restored to the active state.

Concentration-response curves were fitted to the Hill equation:

$$
I\left(C_{a}\right)=\frac{Y_{\max } \times C_{a}^{H}}{C_{a}^{H}+E C_{50}^{H}}
$$

where $C_{a}$ is the agonist concentration, $\mathrm{Y}_{\max }$ is the extrapolated maximal value of the response to a saturating concentration of the agonist, $\mathrm{I}\left(\mathrm{C}_{\mathrm{a}}\right)$ is the relative value of the membrane current, $\mathrm{EC}_{50}$ is the agonist concentration inducing $50 \%$ of the maximal response, and $\mathrm{H}$ is the Hill coefficient.

Inhibition curves were fitted to the simple inhibition curve:

$$
\frac{Y_{L}}{Y_{\text {cont }}}=\frac{I C_{50}^{H}}{I C_{50}^{H}+L^{H}}
$$

where $Y_{L}$ is the current response amplitude after agonist and lobeline application, $Y_{\text {cont }}$ is the control response to the agonist, $I C_{50}$ is the inhibitor concentration that inhibits $50 \%$ of the control response, $H$ is the Hill coefficient for inhibition and $L$ is the concentration of inhibitor.

\section{Calcium mobilization assay}

\section{Cell culturing}

Chinese hamster ovary cells (CHO-M1WT2, CRL-1984) stably expressing human recombinant $\mathrm{M}_{1} \mathrm{mAChR}$ (70 fmol/ $\mathrm{mg}$ ) were obtained from ATCC. Cells were cultured in Ham's F-12 medium supplemented with fetal bovine serum $(10 \%)$ and geneticin $(50 \mathrm{ng} / \mathrm{ml})$. Cells were maintained at $37^{\circ} \mathrm{C}$ in an atmosphere of $5 \% \mathrm{CO}_{2}$.

\section{Fluo-4 NW Assay}

Cells were plated out at a density of $\approx 70,000$ cells per well in $100 \mu \mathrm{l}$ of medium, in a black-walled, clear-bottomed 96-well plate (Biotech, Czech Republic), and were grown overnight at $37^{\circ} \mathrm{C}$ in an atmosphere of $5 \% \mathrm{CO}_{2}$. The next day, the medium was removed leaving the cells adhering to the bottom. $100 \mu \mathrm{l}$ of Fluo-4NW solution was added. Fluo-4NW solution was prepared according to manufacturer's protocol $-10 \mathrm{ml}$ of Hank's balanced salt solution (HBSS buffer) and $100 \mu \mathrm{l}$ of probenecid solution were added to the dye mixture. Cells were incubated with the dye for $30 \mathrm{~min}$ at $37^{\circ} \mathrm{C} / 5 \% \mathrm{CO}_{2}$ in the dark and $30 \mathrm{~min}$ at room temperature.

The tested compounds were dissolved in DMSO and diluted 150 times with distilled water on the day of experiment, and stock concentrations were prepared in the HBSS buffer. Stock solution was pipetted to a well to achieve the final concentration. The final concentration of DMSO in the well did not exceed $0.3 \%(\mathrm{v} / \mathrm{v})$.

The effect of the novel compounds was compared to BQCA, a positive allosteric modulator standard. Cells were pre-incubated with the tested compound $(10 \mu \mathrm{l} /$ well $)$ for 10 minutes and then $\mathrm{EC}_{20}$ of oxo-M (30 nmol/l) was applied. Since the compounds inhibited the $\mathrm{EC}_{20}$ Oxo- $\mathrm{M}$ response, their inhibitory potency was measured at $\mathrm{EC}_{80}$ oxo-M $(1 \mu \mathrm{mol} / \mathrm{l}) . \mathrm{Ca}^{2+}$ influx was measured by plate reader Synergy HT (Biotek, USA) at an excitation and emission wavelength of 485/20 nm and 528/20 nm, respectively. All measurements were made at room temperature $\approx 21^{\circ} \mathrm{C}$.

Responses were quantified as the maximum response expressed as a percentage of the average baseline values and normalized to the control. The first and last wells received oxo-M ( $1 \mu \mathrm{mol} / \mathrm{l}$ or $30 \mathrm{nmol} / \mathrm{l})$ and served as controls. The mean was considered to be a $100 \%$ response in order to minimize time-dependent errors (fading of responses), which were observed in the longer-lasting experiments. Data were fitted using a standard four-parameter equation GraphPad Prism 5.0 (San Diego, CA) to generate graphs, $\mathrm{IC}_{50}$ and SEM.

\section{Contraction study}

\section{Tissue preparation}

Male Wistar rats (bodyweight 250-320 g) were anaesthetized with pentobarbitone ( $45 \mathrm{mg} / \mathrm{kg}$; i.p.). Thereafter, the urinary bladders were removed and two urinary strips $(6 \times 2 \mathrm{~mm})$ were dissected. Strips were mounted into organ baths $(25 \mathrm{ml})$ between two electrodes where one of the holders was fixed and the other moveable. The organ bath was filled with Krebs solution $\left(\mathrm{NaCl} 118, \mathrm{KCl} 4.6, \mathrm{CaCl}_{2} 1.25, \mathrm{KH}_{2} \mathrm{PO}_{4}\right.$ $1.15, \mathrm{MgSO}_{4} 2.26, \mathrm{NaHCO}_{3} 25$ and glucose 5.5 in $\mathrm{mmol} / \mathrm{l}$ ) aerated with a mixture of $5 \% \mathrm{CO}_{2}$ and $95 \% \mathrm{O}_{2}$ and maintained at constant temperature $\left(37^{\circ} \mathrm{C}\right)$ by a thermo-regulated water circuit. Strips were left 45 minutes in a solution with a stable tension of about $5 \mathrm{mN}$ and repeatedly pre-stretched as needed. 


\section{Experimental protocol}

The strips were left to equilibrate for 45-60 min before the experiment. The contractile responses (induced by electric field stimulation (EFS), by metacholine (MCh) or by adenosine triphosphate (ATP)) were used for the examination of the AChEI effect on rat bladder. Firstly, control responses were obtained. EFS was employed at increased frequencies $(1,2,5$, 10,20 and $40 \mathrm{~Hz}$ ) delivered as square wave pulses. The strip was then allowed to equilibrate for at least $20 \mathrm{~min}$. MCh was administered in a cumulative manner in concentrations from $10^{-8} \mathrm{~mol} / \mathrm{l}$ to $10^{-3} \mathrm{~mol} / \mathrm{l}$ and then the strip was washed three times. Thereafter, ATP was added $\left(10^{-6} \mathrm{~mol} / \mathrm{l}\right.$ to $5 \times 10^{-3}$ mol/l). The tested compound, 7-MEOTA or compound 2 , was then added to achieve the final concentrations $10^{-6}$ $\mathrm{mol} / \mathrm{l}, 10^{-5} \mathrm{~mol} / \mathrm{l}$ and $10^{-4} \mathrm{~mol} / \mathrm{l}$ in the organ bath chambers. The contraction responses to EFS, MCh and ATP were recorded after administration of the test compound in each concentration. A 20 min resting period was applied between each measurement, and after addition of MCh or ATP into the organ bath, the whole bath was washed three times. All drugs were administered cumulatively in a volume of $125 \mu \mathrm{l}$ at a 200 times larger concentration in order to achieve the correct final concentration in the organ bath chambers. Responses were recorded by MP100WSW data acquisition system (Biopac, Goleta, USA). Results were evaluated by statistical program GraphPad Prism 5.0 (San Diego, CA) to generate the graphs, $\mathrm{IC}_{50}$ and $\mathrm{SD}$.

\section{Modified PAMPA assay}

Penetration across the BBB is an essential property for compounds targeting the CNS. In order to predict the passive $\mathrm{BBB}$ penetration of the novel compounds, the parallel artificial membrane permeation assay (PAMPA) was used according to a slightly modified protocol (Di et al. 2003). The tested compounds were dissolved according to their solubility properties directly in PBS pH 7.4 buffer (7-MEOTA $300 \mu \mathrm{mol} / \mathrm{l})$. Donepezil $(100 \mu \mathrm{mol} / \mathrm{l})$ and the 7-MEOTA-donepezil derivatives were first dissolved in DMSO in order to prepare a stock solution $(1.2 \mathrm{mmol} / \mathrm{l})$, which was subsequently further diluted in the $\mathrm{PBS}$ pH 7.4 buffer to achieve the final concentration in the donor well
(300 $\mu \mathrm{mol} / \mathrm{l})$. The concentration of DMSO in the well was always below $0.5 \%(\mathrm{v} / \mathrm{v}) .250 \mu \mathrm{l}$ of the solution was added to the donor wells. The filter membrane was coated with PBL in dodecane ( $4 \mu \mathrm{l}$ of $20 \mathrm{mg} / \mathrm{ml} \mathrm{PBL}$ in dodecane) and the acceptor well was filled with $500 \mu$ l of PBS pH 7.4 buffer. The donor filter plate was carefully put on the acceptor plate so that the coated membrane was "in touch" with both the donor solution and the acceptor buffer. The test compound diffused from the donor well through the lipid membrane and into the acceptor well. The set was left undisturbed for $24 \mathrm{~h}$ while permeation progressed. The concentration of drug in the acceptor well and in the reference wells (standard curve) was determined using the UV plate reader Biotek Synergy HT at the maximum absorption wavelength (360 nm for 7-MEOTA-donepezil derivatives, $270 \mathrm{~nm}$ for donepezil and $250 \mathrm{~nm}$ for 7-MEOTA). The concentration of the compounds was calculated from the standard curve and the membrane permeation was expressed in percentage; i.e. the ratio of the concentration assessed in the acceptor well and the concentration applied into the donor well.

\section{Results}

In order to characterize the therapeutic potential of novel 7-MEOTA - donepezil derivatives, a series of in vitro experiments were carried out involving evaluation of interaction of novel derivatives and their parent compound with AChE, with various subtypes of muscarinic muscle-type of nicotinic receptors. Furthermore, BBB penetration was estimated as a prime prerequisite for a centrally-acting drug. The investigation describing the mechanism of action was mainly of a comparative nature, i.e. it compares the properties of the new drugs with an already approved drug (7-MEOTA).

\section{Interaction with AChE}

The kinetic Lineweaver-Burk analysis was applied in order to investigate the affinity of the compounds and the mechanism of inhibition. $\mathrm{IC}_{50}$ (the concentration of tested compound that inhibits AChE activity to 50\%), the $K_{i}$ constants (the dissociation constant of the enzymeinhibitor complex into free enzyme and inhibitor) and

Table 1. AChE inhibition constants for tested compounds

\begin{tabular}{lccc}
\hline & $\mathrm{IC}_{50}(\mu \mathrm{mol} / \mathrm{l})$ & $\mathrm{Ki}\left(\mu \mathrm{mol} / 1^{-1} \cdot \mathrm{min}^{-1}\right)$ & Type of inhibition \\
\hline 7-MEOTA & $10.50 \pm 2.00^{\mathrm{a}}$ & $1.50 \pm 0.15$ & Noncompetitive \\
Compound 1 & $1.38 \pm 0.15^{\mathrm{a}}$ & $0.02 \pm 0.01$ & Mixed \\
Compound 2 & $1.59 \pm 0.32^{\mathrm{a}}$ & $0.29 \pm 0.05$ & Mixed \\
Compound 3 & $12.91 \pm 0.70^{\mathrm{a}}$ & $4.62 \pm 0.74$ & Mixed \\
\hline
\end{tabular}

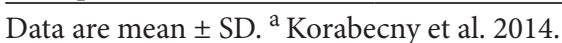


type of inhibition are summarized in Tab. 1. The graphical analysis of steady state inhibition data is presented in Fig. 2. 7-MEOTA demonstrated classical noncompetitive inhibition. It binds reversibly, randomly and independently at the different sites of the enzyme. On the other hand, the data for compounds 1, 2 and $\mathbf{3}$ indicated a mixed type of inhibition. This type of inhibition generally resulted in a combination of partially competitive and pure noncompetitive inhibitions and points towards inhibitors having a dual-binding site feature. Such characteristics assume binding into the active site as well as into the peripheral anionic site (PAS) of AChE at the same time.

\section{Interaction with nicotinic receptors}

Interaction of new AChEIs (compounds 1, 2, 3) on AChinduced $(100 \mu \mathrm{mol} / \mathrm{l})$ with muscle-type nicotinic receptors has been investigated using the patch clamp technique. The inhibitory effect on ACh-induced $(100 \mu \mathrm{mol} / \mathrm{l})$ currents in the presence of increasing concentrations $\left(3 \times 10^{-6}-10^{-4}\right.$ $\mathrm{mol} / \mathrm{l}$ ) of new drugs was investigated. AChEIs were administered $5 \mathrm{~s}$ before Ach.

We used human embryonic muscle type receptor $\alpha_{1} \beta_{1} \gamma$ stably expressed by the TE671 cell line. All tested compounds inhibited the ACh-evoked response in a dose-dependent manner (Fig. 3). Compound 3 showed the most pronounced inhibitory potency of the ACh-evoked $(100 \mu \mathrm{mol} / \mathrm{l})$ response $\left(\mathrm{IC}_{50}=1.7 \pm 0.9 \mu \mathrm{mol} / \mathrm{l}\right)$. The other tested compounds inhibited the nicotinic muscle receptor response at the same order of magnitude, but with slightly lower potency (compound 1: $\mathrm{IC}_{50}=3.6 \pm 0.3 \mu \mathrm{mol} / \mathrm{l}$, compound 2: $\mathrm{IC}_{50}$ $=6.8 \pm 2.6 \mu \mathrm{mol} / \mathrm{l}) .7$-MEOTA has previously been tested and shows a similar concentration-dependent curve $\left(\mathrm{IC}_{50}\right.$ $=3.7 \mu \mathrm{mol} / \mathrm{l})$. However, it should be pointed out that in the previous investigations the concentration of ACh was $30 \mu \mathrm{mol} / \mathrm{l}$ (data not shown).
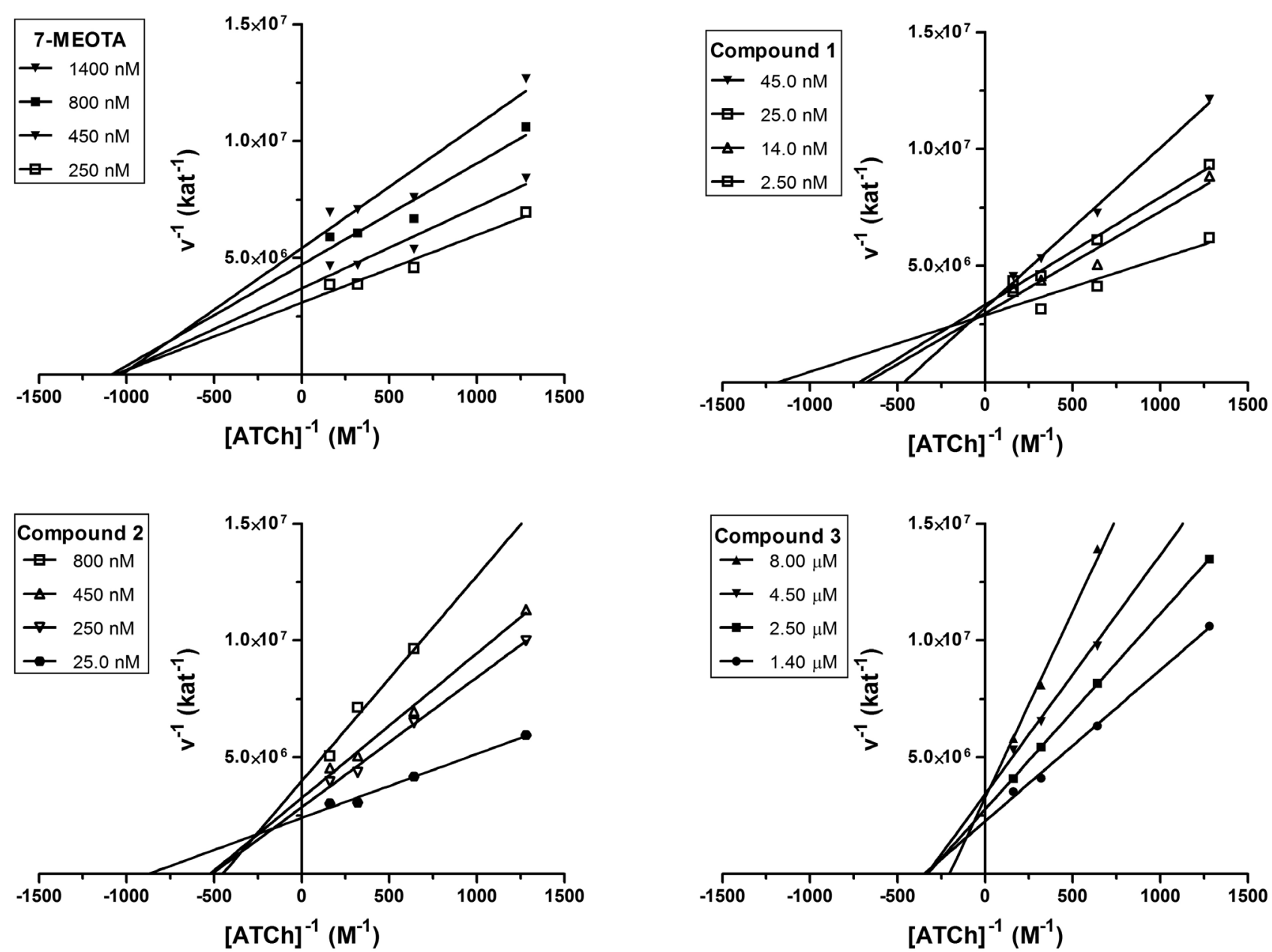

Figure 2. Lineweaver-Burk analysis of $h r A C h E$ inhibition by 7-MEOTA, compounds $\mathbf{1}, 2$ and $\mathbf{3}$. The reciprocal plots show noncompetitive type inhibition for 7-MEOTA and compound $\mathbf{1}$, and mixed type of inhibition for compounds $\mathbf{2}, \mathbf{3}$. 


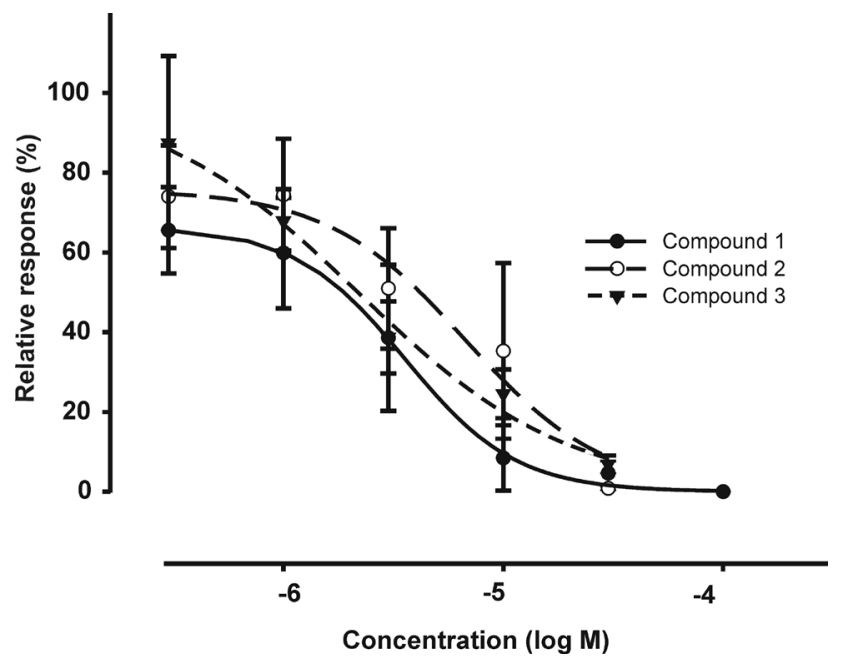

Figure 3. Antagonistic effect of tested AChEIs. Inhibitory effect of tested AChEIs (Compounds 1, 2, 3) on ACh-induced currents. Decrease of ACh $(100 \mu \mathrm{mol} / \mathrm{l})$ response amplitudes with increasing concentrations $\left(3 \times 10^{-6}-10^{-4} \mathrm{~mol} / \mathrm{l}\right)$ of AChEIs. AChEIs were pre-applied $5 \mathrm{~s}$ before Ach.

\section{Interaction with $M_{1}$ muscarinic receptors}

The effect of 7-MEOTA and its derivatives on the muscarinic receptor-mediated response was assessed in $\mathrm{CHO}-\mathrm{K} 1$ cells stably expressing the $\mathrm{M}_{1}$ subtype of $\mathrm{mAChR}$, using calcium mobilization assay (Fig. 4). For comparison, atropine, the classic antagonist of $\mathrm{mAChR}$, and BQCA, a standard allosteric agonist, were used in order to investigate the mechanism of interaction. The novel compounds 1, 2, 3 and 7-MEOTA, exhibited an antagonistic effect on $M_{1}$ muscarinic receptors, similar in type to that of atropine. However, such effect was observed at completely different concentration ranges. Atropine $\left(\mathrm{IC}_{50}=(59 \pm 13) \times 10^{-9}\right.$ $\mathrm{mol} / \mathrm{l}$ ), was a 300 -fold more effective antagonist than the novel inhibitors series. The parent compound 7-MEOTA

Table 2. Inhibition ability of tested compounds on nicotinic muscletype and muscarinic $\mathrm{M}_{1}$ receptor

\begin{tabular}{lcc}
\hline & $\begin{array}{c}\mathrm{nACHR} \mathrm{IC}_{50} \\
(\mu \mathrm{mol} / \mathrm{l})\end{array}$ & $\begin{array}{c}\mathrm{mAChR} \mathrm{M}_{1} \mathrm{IC}_{50} \\
(\mu \mathrm{mol} / \mathrm{l})\end{array}$ \\
\hline 7-MEOTA $^{\mathrm{a}}$ & $3.7 \pm 0.3$ & $3.05 \pm 0.47$ \\
Compound 1 $_{\text {Compound 2 }}$ & $3.6 \pm 0.3$ & $23.17 \pm 2.18$ \\
Compound 3 & $6.8 \pm 2.6$ & $20.02 \pm 7.49$ \\
Atropine & $1.7 \pm 0.9$ & $38.18 \pm 3.99$ \\
\hline
\end{tabular}

Data are mean \pm SD of three to independent experiments, each from different cells (nAChR) and at least two experiments in triplicate (mAChR). ${ }^{\mathrm{a}}$ 7-MEOTA was tested with $30 \mu \mathrm{mol} / \mathrm{l}$, others with 100 $\mu \mathrm{mol} / \mathrm{l}$; nt, non tested.

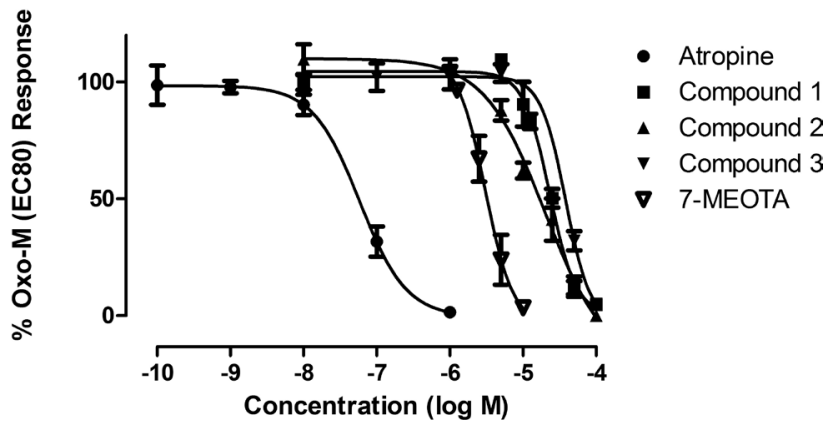

Figure 4. Antagonistic effect of tested compounds on $\mathrm{M}_{1}$ muscarinic receptors. Inhibition curves were obtained in the presence of $\mathrm{EC}_{80}$ Oxo-M $(1 \mu \mathrm{mol} / \mathrm{l})$. Data represent the mean \pm SEM of three measurements.

was able to inhibit $M_{1}$ muscarinic receptor in a concentration range one order of magnitude lower than the 7-MEOTA-donepezil derivatives (see Tab. 2).

None of the tested compounds showed any potentiating effect on the M1 muscarinic receptor as does BQCA (Fig. 5).

\section{Contraction study}

The functional significance of the binding characteristics demonstrated above (i.e. inhibition of AChE and muscarinic receptors) was examined in the rat urinary bladder, a complex model involving both of these targets. Three types of stimulation - EFS and agonist stimulation by MCh and ATP, were applied in order to evoke contractions of the isolated bladder strip preparations on which the effects of 7-MEOTA and one 7-methoxytacrine-donepezil derivative (compound 2) were examined (Fig. 6). Since EFS leads to the release of all the transmitters within the bladder innerva-

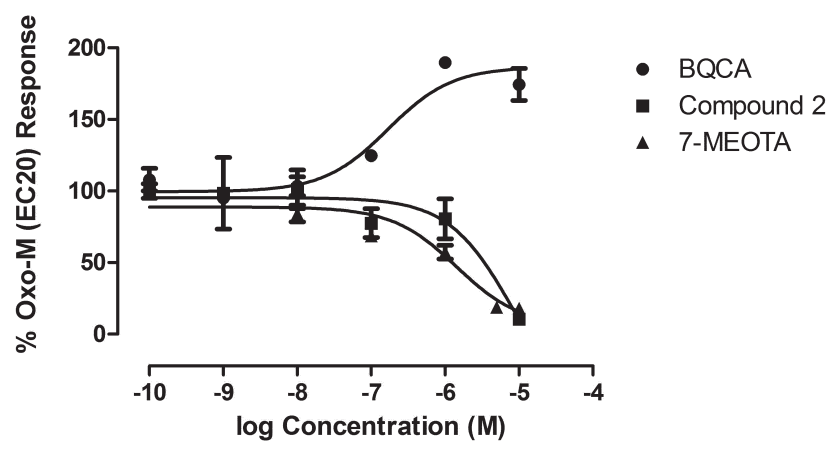

Figure 5. Effect of novel compound 2 and standard BQCA on CHO- $\mathrm{M}_{1} \mathrm{WT} 2$ cells stably expressing $\mathrm{M}_{1} \mathrm{mAChR}$. Increasing concentrations of tested compounds were added to wells and incubated for $10 \mathrm{~min}$. $\mathrm{EC}_{20}$ of Oxo-M was then added. Data represent the mean \pm SEM of three measurements. 
tion, specifically acetylcholine and ATP that are co-stored in the rat parasympathetic neurons (Vesela et al. 2012), MCh and ATP were employed for distinguishing the cholinergic and the purinergic effects (Werner et al. 2007). All three types of stimulation evoked contractions that were enlarged by increasing the intensity of the stimulation. Analyses employing a two-way ANOVA revealed the basal responses (responses in the absence of any derivate in the EFS, MCh and ATP groups) not to be significantly different in any group. EFS thus induced frequency-dependent contractions. The maximum responses occurred in the range of $20-40 \mathrm{~Hz}$ and were $17.9 \pm 2.7$ and $17.0 \pm 4.0 \mathrm{mN}$ in the 7-MEOTA and compound 2 -treated groups, respectively. The nonselective muscarinic receptor agonist MCh, which is resistant towards AChE cleavage, evoked concentration-dependent contractile responses showing maximums of $26.0 \pm 3.2$ and
7- Meota
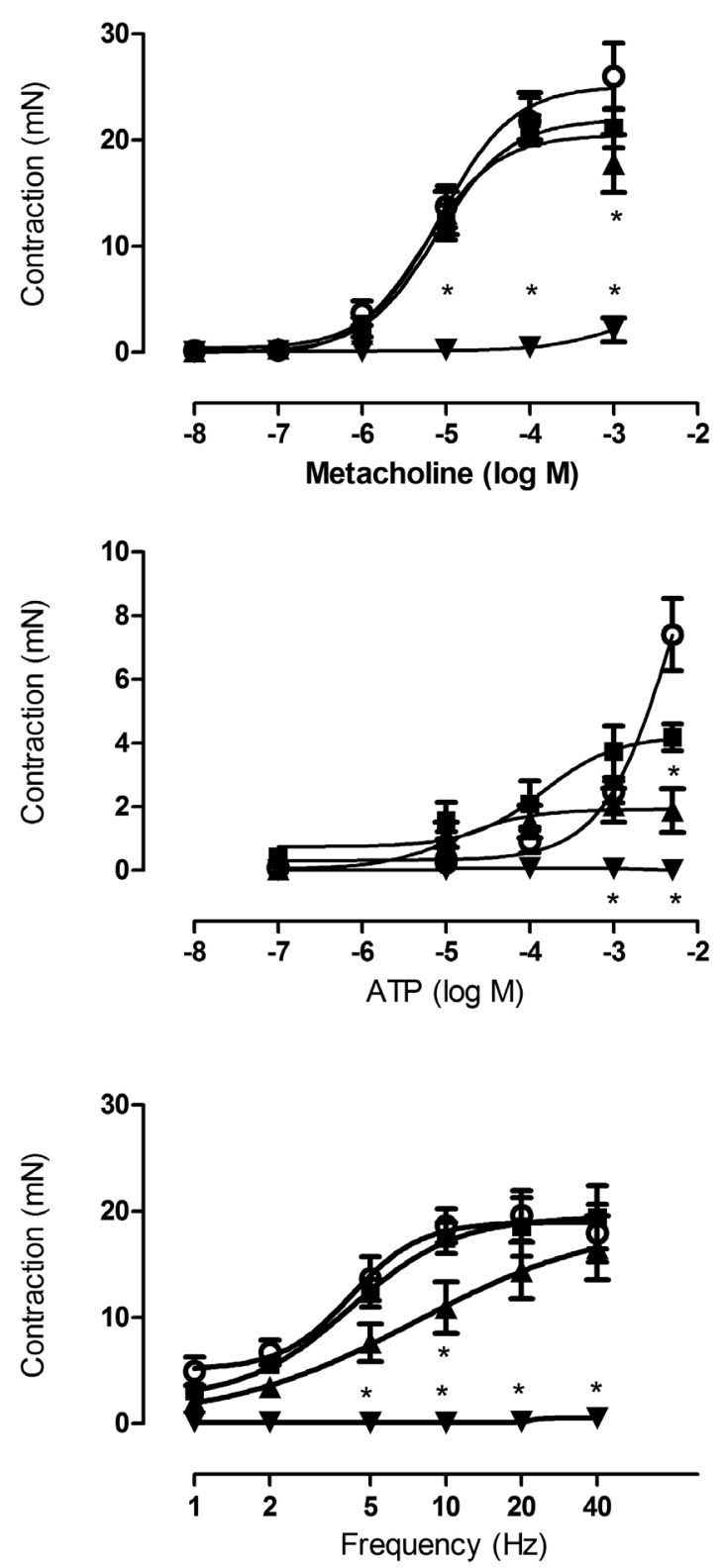

\section{Compound 2}
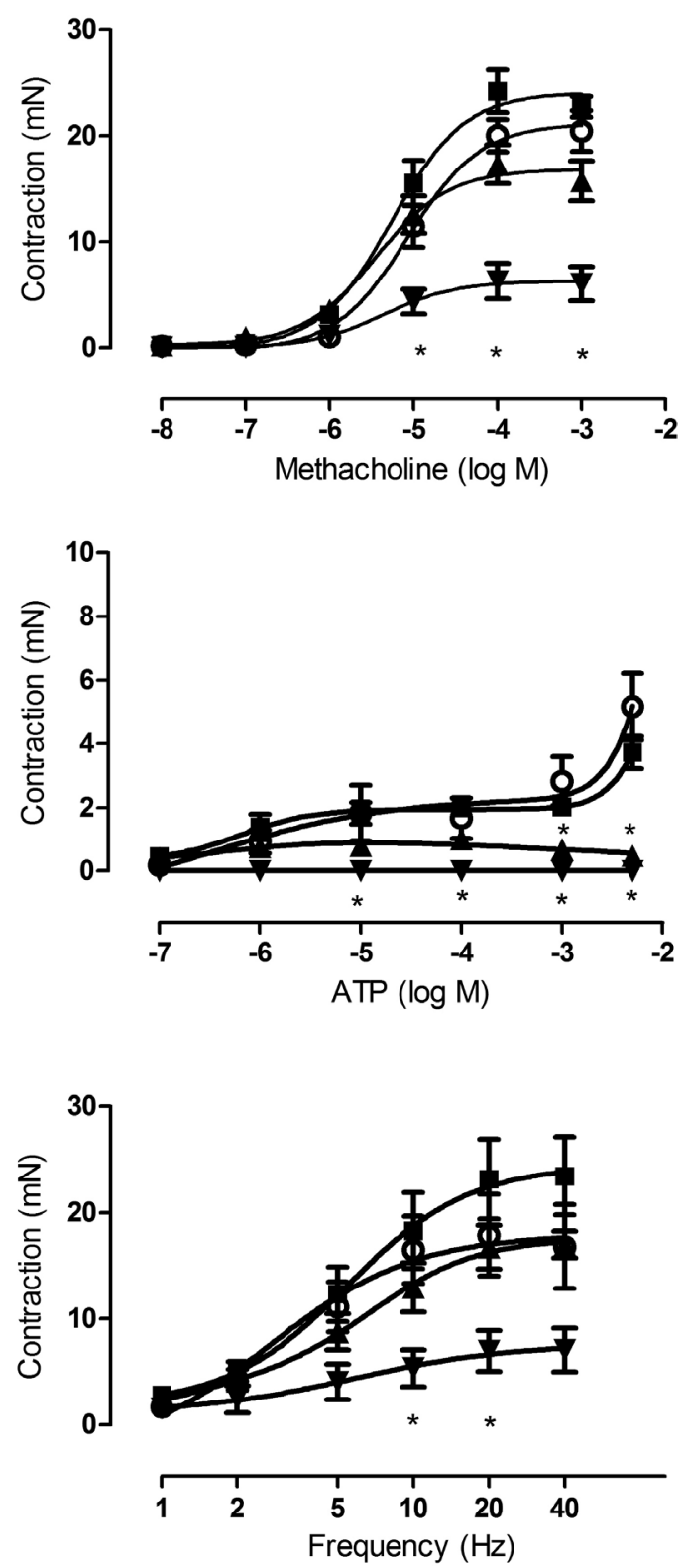

Figure 6. Data from 7-MEOTA (left column) and from compound 2 (right column) in the contraction study. Graph in absence $(\bigcirc)$ and presence of $10^{-4} \mathrm{~mol} / \mathrm{l}(\boldsymbol{\nabla}), 10^{-5} \mathrm{~mol} / \mathrm{l}(\boldsymbol{\Delta})$, and $10^{-6} \mathrm{~mol} / \mathrm{l}(\boldsymbol{\square})$ of tested compounds. 
$20.4 \pm 2.0 \mathrm{mN}$ for the 7-MEOTA- and compound 2-treated groups, respectively. ATP evoked smaller contractions but no maximum response could be identified at the concentration range used currently. At the largest concentration used, the contractile responses were $7.4 \pm 1.1$ and $5.2 \pm 1.0 \mathrm{mN}$ for the 7-MEOTA- and compound 2-treated groups, respectively. A tendency to biphasic concentration-dependent responses to ATP was indicated. A first phase showed a pEC50 of 6.5 (merged data from both groups). The second phase of the response appeared at ATP concentrations higher than $10^{-5}$ $\mathrm{mol} / \mathrm{l}(7.3 \pm 1.1$ and $5.2 \pm 1.0 \mathrm{mN}$, for the 7-MEOTA- and compound 2-groups, respectively).

The presence of the compounds (7-MEOTA and compound 2$)$ at the lowest concentration examined $\left(10^{-6} \mathrm{~mol} / \mathrm{l}\right)$ showed no or little inhibition of the ATP-evoked responses. At the higher concentrations, and in particular at the highest concentration $\left(10^{-4} \mathrm{~mol} / \mathrm{l}\right)$, significant decreases in the contractions occurred $(p<0.05)$. The same pattern appeared for the largest concentration of the derivatives for the EFS- as well as the MCh-evoked responses, tentatively indicating non-specific effects. A concentration of $10^{-5} \mathrm{~mol} / \mathrm{l}$ of MEOTA still tended to inhibit the contractions to EFS $(18.6 \pm 1.6$ vs. $10.9 \pm 2.4 \mathrm{mN}$ at $10 \mathrm{~Hz})$ in the presence and absence of 7-MEOTA, respectively $(p<0.01)$. However, this was the only significant change, if disregarding the $10^{-4} \mathrm{~mol} / \mathrm{l}$ concentration. For compound 2, no significant changes occurred regarding EFS with the exception of the $10^{-4} \mathrm{~mol} / \mathrm{l}$ concentration. 7 -MEOTA at $10^{-5} \mathrm{~mol} / 1$ significantly reduced the methacholine-evoked response. In the absence of 7-MEOTA, the contractile response to methacholine at $10^{-3} \mathrm{~mol} / \mathrm{l}$ was $26.0 \pm 3.1 \mathrm{mN}$, whereas in its presence it was $17.8 \pm 2.7 \mathrm{mN}(p<0.001 ; n=7)$.

\section{$B B B$ penetration estimation}

The ability to penetrate the $\mathrm{BBB}$ is a main prerequisite for a centrally-acting drug. The modified PAMPA assay showed that all new compounds readily penetrate across the lipophilic membrane by passive diffusion. Except for compound 2, the drugs showed similar penetration abilities as the parent compound 7-MEOTA (Tab. 3), which has been proved to cross BBB (Soukup et al. 2013). Donepezil, which was used as a model of a CNS-permeable drug, confirmed an adequate experimental setup by its high penetration rate (87\%).

\section{Discussion}

The area of prophylaxis against organophosphates still needs further exploration. Different approaches have been investigated but many problems have been found. After administration of stoichiometric or catalytic scavengers (e.g. butyrylcholinesterase or phosphotriesterase) immunologic reactions were invoked (Bajgar 2004; Lenz et al. 2007), and their use is limited to experimental purposes due to high cost. Administration of anticonvulsants shows low prophylactic efficiency. Also, some problems have been reported regarding reactivators (Bajgar 2005), principally regarding the route of administration due to their fast metabolism, but also due to their fast excretion. Recently, prophylaxis against nerve gases has focused predominantly on reversible AChE inhibitors. One of such medicaments, PANPAL, was introduced into the Czech Army in 2002 (Bajgar 2004). Pyridostigmine, which is not effective in the brain at lower doses, was combined with trihexyphenidyl and benactyzine that mitigate peripheral side effects, so that a higher dose of pyridostigmine can be applied. Furthermore, both anticholinergics penetrate to the central compartment, where they are able to protect the cholinergic receptors from the overstimulation of $\mathrm{ACh}$ during the poisoning. It has been demonstrated that exposure of pyridostigmine alone can lead to neurobehavioral deficits and region-specific alterations of AChE and AChR (Abou-Donia et al. 2001). Albequerque et al. (1985) presented that physostigmine (coapplied with atropine) combined with a ganglionic blocking drug mecamylamine was the most effective medication for protecting rats against lethal doses of VX.

Accordingly we started to look for a new compound, which would be able to protect AChE and simultaneously AChR against organophosphate intoxication. Inspired by the positive 7-MEOTA results and its efficacy in VX poisoning prophylaxis (Bajgar et al. 1983), and the "PANPAL" approach, we investigated how 7-MEOTA derivatives are able to influence AChE, AChR activity, and the mechanism of action of such hybrid compounds.

The new 7-MEOTA-donepezil derivatives exerted more potent (compound 1,2) or similar (3) AChE-inhibitory activity compared to 7-MEOTA. 7-MEOTA has been reported to be a better AChE inhibitor than pyridostigmine (Lorke et

Table 3. AChE inhibitors permeation ability

\begin{tabular}{lcc}
\hline & Permeation (\%) & $\mathrm{R}^{2}$ \\
\hline 7-MEOTA & 66 & 0.9898 \\
Compound $\mathbf{1}$ & 63 & 0.9974 \\
Compound 2 & 44 & 0.9940 \\
Compound 3 & 62 & 0.9970 \\
Donepezil & 87 & 0.9829 \\
\hline
\end{tabular}

The degree of membrane permeation of the compounds expressed in percentage, i.e. the ratio of the concentration assessed in the acceptor well (as a result of the membrane penetration) and of the concentration applied into the donor well. Linearity of the standard curve was proved by the determination coefficient represented as $R^{2}$. 
al. 2011). Moreover, as has been said above, pyridostigmine does not penetrate the BBB (Dunn et al. 1997) and it is not able to offer protection against seizures and subsequent neuropathology induced by organophosphates, especially in cases of soman-induced toxicity (Dunn et al. 1997). On the contrary, 7-MEOTA is able to pass the BBB (Kunes et al. 2005). Based on the fact that 7-MEOTA and donepezil alone cross the barrier (Kim et al. 2010), we presumed that 7-MEOTA-donepezil hybrids might penetrate the BBB too. The modified PAMPA assay showed that all new compounds readily penetrate across the lipophilic membrane by passive diffusion. Data have shown that a possible solution for this matter is co-administration of AChEI and the muscarinic antagonist scopolamine, which speaks in favour of our hypothesis.

The $M_{1}$ subtype of $m A C h R$ is abundantly found in the cortex and hippocampus (Fisher et al. 2002), whilst a small population of $\mathrm{M}_{1}$ appears in salivary glands and the presynaptic area of the bladder parasympathetic nervous system (Tobin 1995; Abrams et al. 2006). Notably, compound 3 is able to cause $50 \%$ inhibition of $\mathrm{AChE}$ and $\mathrm{M}_{1} \mathrm{mAChR}$ in the same concentration range, whilst compounds $\mathbf{1}$ and $\mathbf{2}$ showed one order of magnitude lower ability to inhibit $M_{1}$ mAChR than AChE. In contrast, 7-MEOTA inhibited $M_{1}$ receptor at a lower concentration $\left(\mathrm{IC}_{50}=3 \mu \mathrm{mol} / \mathrm{l}\right)$ than it inhibits $\mathrm{AChE}\left(\mathrm{IC}_{50}=10 \mu \mathrm{mol} / \mathrm{l}\right)$. None of the compounds showed any ability to potentiate the M1 muscarinic receptor effect. From this point of view, compound 3 possesses promising in vitro antimuscarinic action on the centrally occurring muscarinic subtype.

Further examination was focused on peripheral receptors. After organophosphate intoxication, the overstimulation of the muscle type of $\mathrm{nAChR}$ that occurs at the motor end-plate in respiratory and other muscles (Sungur et al. 2001) is followed by fasciculation and weakness, eventually resulting in asphyxiation. Thus, the hypothesis of using a nAChR antagonist was developed. Sheridan et al. (2005) pointed out the difficulties of administering a dose of a compound that antagonizes the effect of excessive ACh, but which does not cause paralysis of muscle. Turner et al. (2011) introduced a non-competitive antagonist on $\mathrm{nAChR}$, which acts as an open channel blocker and is able to protect guinea pigs against poisoning by nerve agents. We observed an antagonist effect in all tested compounds on the muscle type of nAChR expressed in TE671 cells. Generally, the effect of the tested AChEI was similar $\left(\mathrm{IC}_{50}=1-3 \mu \mathrm{mol} / \mathrm{l}\right)$. However, compounds $\mathbf{1}$ and $\mathbf{2}$ inhibited AChE in comparable concentrations to those acting on the nicotinic receptor; whereas 7-MEOTA and compound 3 needed to be administered at higher concentrations to inhibit AChE. Moreover, 7-MEOTA has been evaluated previously, concerning how it influences the neuronal $\alpha 4 \beta 2$ nicotinic receptor (Soukup et al. 2013). 7-MEOTA interacts slightly more effectively with muscular than neuronal nAChR $\left(\mathrm{IC}_{50}=4 \mu \mathrm{mol} / \mathrm{l}\right.$, respectively $15 \mu \mathrm{mol} / \mathrm{l})$.

The effect on peripheral mAChR $\left(\mathrm{M}_{2}\right.$ and $\mathrm{M}_{3}$ subtype) was examined employing an organ model (rat urinary bladder). When applying EFS, the antagonistic effect of 7-MEOTA and compound 2 was evident. However, it was not clear whether the cholinergic pathway is the only pathway involved. Furthermore, 7-MEOTA in high concentration completely inhibited the strip contractions. Since an atropine-resistant bladder contraction exists (Andersson and Wein 2004) and since 7-MEOTA completely inhibited the nerve-evoked response, 7-MEOTA is not likely to affect only the cholinergic pathway. Hence we applied MCh (mAChR agonist) and ATP (P2X purinoreceptor agonist) to distinguish the different mechanisms of action influencing the contraction. Even though compound $\mathbf{2}$ is a derivative of 7-MEOTA, it acts through a different pathway. Compound 2 inhibits contraction induced by MCh through $\mathrm{mAChR}$ in a concentration-dependent manner and the highest concentration tested $\left(10^{-4} \mathrm{~mol} / \mathrm{l}\right)$ resulted in 3-times weaker contractions than MCh did on its own. On the other hand, 7-MEOTA caused less inhibition of the muscarinic response, and at $10^{-4} \mathrm{~mol} / \mathrm{l}$ the contraction almost completely vanished. Differences in inhibition of purinoreceptor effects also occurred, but there seems to be an opposite action. 7-MEOTA decreases contractions in a concentration-dependent manner and compound $\mathbf{2}$ antagonism on P2X receptors is rather subtle. This is confirmed by the EFS stimulation. At low frequencies, the purinergic-mediated force is enhanced (Werner et al. 2007). Thus 7-MEOTA inhibits contraction at low frequencies, and in high concentration $\left(10^{-4} \mathrm{~mol} / \mathrm{l}\right)$ completely inhibits bladder contraction to EFS even at higher frequencies $(40 \mathrm{~Hz})$. Note that a concentration-dependence can be observed in the ATP-evoked contraction that indicates 7-MEOTA has a higher effect on the purinergic rather than the cholinergic pathway. On the other hand, the contractile reaction is maintained in the presence of compound $\mathbf{2}$ (at all concentrations) in response to EFS, while a dose-dependence is observed on the MCh-evoked contractions. Thus it seems that antagonism on the purinergic $\mathrm{P} 2 \mathrm{X}$ receptors is absent or smaller than the effect on the cholinergic system. However, it cannot be completely ruled out.

In conclusion, this study provides evidence that the newly synthesized 7-MEOTA-donepezil derivatives have anticholinergic effect; in vitro and ex-vivo experiments showed that they can inhibit AChE, nAChR and mAChR of both peripheral and central types. Furthermore, their mechanisms of interaction were elucidated. Overall, 7-MEOTA- donepezil hybrids represent promising compounds whose features could be an effective way to diminish the effect of overstimulation of cholinergic receptors during organophosphate poisoning. However, their real 
prophylactic potency and benefit must be definitively verified in vivo.

Acknowledgement. The present study was supported by grant Ministry of Defence, A long-term developing plan 1011, by $\mathrm{MH}$ CZ - DRO (University Hospital Hradec Kralove, No. 00179906), and long-term conceptual development of research organization RVO: 67985823. The authors would also like to thank to the Grant Agency (Czech Republic) No. P303/11/1907 and the National Institute of Mental Health (NIMH-CZ), grant number CZ.1.05/2.1.00/03.0078 and the European Regional Development Fund.

\section{References}

Abrams P., Andersson K. E., Buccofusco, J. J., Chapple C., Chet de Groat W., Fryer A. D., Kay G., Laties A., Nathanson N. M., Pasricha P. J., Wein A. J. (2006): Muscarinic receptors: their distribution and function in body systems, and the implications for treating overactive bladder. Brit. J. Pharmacol. 148, $565-578$

http://dx.doi.org/10.1038/sj.bjp.0706780

Abou-Donia M. B., Goldstein L. B., Jones K. H., Abdel-Rahman A. A., Damodaran T. V., Dechkovskaia A. M., Bullman S. L., Amir B. E., Khan W. A. (2001): Locomotor and sensorimotor performance deficit in rats following exposure to pyridostigmine bromide, DEET, and permethrin, alone and in combination. Toxicol. Sci. 60, 305-314 http://dx.doi.org/10.1093/toxsci/60.2.305

Ago Y., Koda K., Kita Y., Fukada A., Takuma K., Matsuda T. (2011): Donepezil, but not galantamine, blocks muscarinic receptor-mediated in vitro and in vivo responses. Synapse 65, 1373-1377

http://dx.doi.org/10.1002/syn.20969

Albequerque E. X., Deshpande S. S., Kawabuch M., Aracava Y., Idriss M., Rickett D. L., Boyne A.F. (1985): Multiple actions of anticholinesterase agents on chemosensitive synapses: Model basis for prophylaxis and treatment of organophosphate poisoning. Fundam. Appl. Toxicol. 5, 182-203

http://dx.doi.org/10.1093/toxsci/5.6part2.182

Andersson K. E., Wein A. J. (2004): Pharmacology of the lower urinary tract: Basis for current and future treatments of urinary incontinence. Pharmacol. Rev. 56, 581-631 http://dx.doi.org/10.1124/pr.56.4.4

Bajgar J., Fusek J., Patocka J., Hrdina V. (1983): Protective effect of 9-amino-7-methoxy-1,2,3,4-tetra-hydroacridine against inhibition of acetylcholinesterase by O-ethyl S-(2-dimethylaminoethyl) methyl phosphonotioate in vivo. Arch. Toxicol. 54, 163-166 http://dx.doi.org/10.1007/BF01261385

Bajgar J. (2004): Organophosphates/nerve agent poisoning: mechanism of action, diagnosis, prophylaxis and treatment. Adv. Clin. Chem. 38, 151-216 http://dx.doi.org/10.1016/S0065-2423(04)38006-6

Bajgar J. (2005): Complex view on poisoning with nerve agents and organophosphates. Acta Medica (Hradec Kralove) 48, $3-21$
Dejmek L. (1990): 7-MEOTA. Drugs Future 15, 126-129 http://dx.doi.org/10.1358/dof.1990.015.02.114543

Di. L., Kerns E. H., Fan K., McConnell O. J., Carter G. T. (2003): High throughput artificial membrane permeability assay for blood - brain barrier. Eur. J. Med. Chem 38, 223-232 http://dx.doi.org/10.1016/S0223-5234(03)00012-6

Dittert I., Vlachova V., Knotkova H., Vitaskova Z., Vyklicky L., Kress M., Reeh P. W. (1998): A technique for fast application of heated solutions of different composition to cultured neurons. J. Neurosci. Methods 82, 195-201 http://dx.doi.org/10.1016/S0165-0270(98)00051-X

Dunn M. A., Hackley B. E., Sidell F. R. (1997): Pretreatment for nerve agent exposure. In: Textbook of Military Medicine: Medical aspects of Chemica and Biological Walfare. (Eds. F. R. Sidell, E. T. Takafuji and D. R. Franz), pp. 181-196, Washington, DC, Borden Institute, Walter Reed Army Medical Center

Fisher A., Branders R., Harring R., Bar-Ner N., Kliger-Spatz M., Natan N., Sonego H., Marcovitch I., Pittel Z. (2002): Impact of muscarinic agonist for successful therapy of Alzheimer's disease. J. Neural. Transm. Suppl. 62, 189-202 http://dx.doi.org/10.1007/978-3-7091-6139-5_18

Jun D., Kuca K., Stodulka P., Koleckar V., Dolezal B., Simon P., Veverka M. (2007): HPLC analysis of HI-6 dichloride and dimethansulfonate - Antidotes against nerve agents and organophosphorus pesticides. Anal. Lett. 40, 2783-2787 http://dx.doi.org/10.1080/00032710701588531

Jun D., Kuca K., Stodulka P., Koleckar V., Dolezal B., Simon P., Veverka M. (2008): TLC analysis of intermediates arising during the preparation of oxime HI-6 dimethylsulfonate. J. Chromatogr. Sci. 46, 316-319 http://dx.doi.org/10.1093/chromsci/46.4.316

Kassa J. (2002): Review of oximes in the antidotal treatment of poisoning by organophosphorus nerve agents. J. Toxicol. Clin. Toxicol. 40, 803-816 http://dx.doi.org/10.1081/CLT-120015840

Ke L., Eisenhour C. M. Benchrif M., Lukas R. J. (1998): Effects of chronic nicotine treatment on expression of diverse nicotinic acetylcholine receptor subtypes. I. Dose- and time-dependent effects of nicotine treatment. J. Pharmacol. Exp. Ther. 286, 825-840

Kim M. H., Maeng H. J., Yu K. H., Lee K. R., Tsuruo T., Kim D. D., Shim C. K., Chung S. J. (2010): Evidence of carrier-mediated transport in the penetration of donepezil into rat brain. J. Pharm. Sci. 99, 1548-1566 http://dx.doi.org/10.1002/jps.21895

Korabecny J., Dolezal R., Cabelova P., Horova A., Hruba E., Ricny J., Sedlacek L., Nepovimova E., Spilovska K., Andrs M. et al. (2014): 7-MEOTA-donepezil like compounds as cholinesterase inhibitors: Synthesis, pharmacological evaluation, molecular modeling and QSAR studies. Eur. J. Med. Chem. 82, 426-438 http://dx.doi.org/10.1016/j.ejmech.2014.05.066

Kunes M., Svoboda Z., Kvetina J., Herout V., Herink J., Bajgar J. (2005): Intestinal single-pass in situ perfusion technique in rat: the influence of L-carnitine on absorption of 7-methoxytacrine. Biomed. Pap. Med. Fac. Univ. Palacky Olomouc Czech Repub. 149, 433-435 http://dx.doi.org/10.5507/bp.2005.075

Leader H., Wolfe A. D., Chiang P. K., Gordon R. K. (2002): Pyridophenes: binary pyridostigmine-aprophen prodrugs with dif- 
ferential inhibition acetylcholinesterase, butyrylcholinesterase, and muscarinic receptors. J. Med. Chem. 45, 902-910 http://dx.doi.org/10.1021/jm010196t

Lenz D. E., Yeung D., Smith J. R., Sweeney R. E., Lumley L. A., Cerasoli D. M. (2007): Stoichiometric and catalytic scavengers as protection against nerve agent toxicity: A mini review. Toxicology 223, 31-39 http://dx.doi.org/10.1016/j.tox.2006.11.066

Lorke D. E., Hasan M. Y., Nurulain S. M., Shafiullah M., Kuca K., Petroianu G. A. (2011): Pretreatment for acute exposure to diisopropylfluorophosphate: in vivo efficacy of various acyetcholinesterase inhibitors. J. Appl. Toxicol. 31, $515-523$

http://dx.doi.org/10.1002/jat.1589

Mayer M. L., Vyklicky L., Clements J. (1989): Regulation of NMDA receptor desensitization in mouse hippocampal neurons by glycine. Nature 338, 425-427 http://dx.doi.org/10.1038/338425a0

Meshulam Y., Cohen G., Chapman S., Alkalai D., Levy A. (2001): Prophylaxis against organophosphate poisoning by sustained release of scopolamine and physostigmine. J. Appl. Toxicol. 21, 575-578 http://dx.doi.org/10.1002/jat.815

Sheridan R. D., Smith A. P., Turner S. R., Tattersall J. E. H. (2005): Nicotinic antagonists in the treatment of nerve agent intoxication. J. R. Soc. Med. 98, 114-115 http://dx.doi.org/10.1258/jrsm.98.3.114

Schoepfer R., Luther M., Lindstrom J. (1988): The human medulloblastom cell line TE671 expresses a muscle-like acetylcholine receptor. Cloning of the alpha-subunit c dna. FEBS Lett. 226, 235-240 http://dx.doi.org/10.1016/0014-5793(88)81430-3

Soukup O., Krusek J., Kaniakova M., Kumar U. K., Oz M., Jun D., Fusek J., Kuca K., Tobin G. (2011): Oxime reactivators and their in Vivo and in Vitro effects on nicotinic receptors. Physiol. Res. 60, 679-686

Soukup O., Jun D., Zdarova K. J., Patocka J., Musilek K., Korabecny J., Krusek J., Kaniakova M., Sepsova V., Mandikova J. et al. (2013): A resurrection of 7-MEOTA: A comparison with Tacrine. Curr. Alzheimer Res. 10, 893-906 http://dx.doi.org/10.2174/1567205011310080011

Sungur M., Güven M. (2001): Intensive care management of organophosphate insecticide poisoning. Crit. Care 5, 211-215 http://dx.doi.org/10.1186/cc1025

Tobin G. (1995): Muscarinic receptor subtypes in the submandibular gland and the urinary bladder of the rabbit: in vivo and in vitro functional comparisons of receptor antagonists. J. Auton. Pharmacol. 15, 451-463 http://dx.doi.org/10.1111/j.1474-8673.1995.tb00410.x

Turner S. R., Chad J. E., Price M., Timperley C. M., Bird M., Green A. C., Tattersall J. E. H. (2011): Protection against nerve agent poisoning by a noncompetitive nicotinic antagonist. Toxicol. Lett. 206, 105-111 http://dx.doi.org/10.1016/j.toxlet.2011.05.1035

Vesela R., Aronsson P., Andersson M., Wsol V., Tobin G. (2012): The potential of non-adrenergic, non-cholinergic targets in the treatment of interstitial cystitis/painful bladder syndrome. J. Physiol. Pharmacol. 63, 209-216

Werner M. E., Knorn A. M., Meredith A. L., Aldrich R. W., Nelson M. T. (2007): Frequency encoding of cholinergic- and purinergic-mediated signaling to mouse urinary bladder smooth muscle: modulation BK channels. Am. J. Physiol. Regul. Integr. Comp. Physiol. 292, 616-624 http://dx.doi.org/10.1152/ajpregu.00036.2006

Received: July 10, 2014

Final version accepted: November 11, 2014

First published online: December 11, 2014 